\title{
Теоретические основы диагностических методик судебного автороведения (на материале письменной межличностной электронной коммуникации)
}

\author{
Е. А. Жданова \\ Ижевский государственный технический университет имени М. Т. Калашникова \\ ул. Студенческая, 7, 426069, Ижевск, 426069, Россия. E-mail: zhdanovaea@gmail.com
}

\begin{abstract}
Статья посвящена исследованию интернет-дискурса в аспекте автороведческой проблематики. В статье рассматриваются специфические черты современной компьютерной коммуникации, жанровые особенности межличностной переписки, оказывающие влияние на язык электронных сообщений. Доказывается, что в интернет-дискурсе иначе проявляются речевые навыки авторов, что требует иного подхода при автороведческом исследовании в данной коммуникативной сфере. Отмечены черты, на которые стоит обратить внимание эксперту при работе с интернет-перепиской. В статье приведены результаты анализа сообщений в социальных сетях и мессенджерах, целью которого было выявление речевых особенностей, указывающих на определенные биологические и социальные признаки авторов. Сообщения в социальных сетях и мессенджерах рассматриваются как явления одного порядка, поскольку они близки функционально, так как служат в основном для неформального обмена информацией между знакомыми друг с другом адресатами, предполагают диалогическое общение преимущественно в письменной форме. В сфере анализа оказались сообщения, написанные лицами мужского и женского пола в возрасте от 12 до 72 лет, имеющими различное образование, занятыми в разных сферах деятельности, являющимися гражданами России и некоторых других стран. В результате анализа выявлены лексико-фразеологические, грамматические, стилистические, орфографические, пунктуационные особенности сообщений авторов в зависимости от их возраста, места происхождения, владения русским языком, уровня образования и общей культуры, профессии и рода занятий. Наиболее показательными признаны особенности лексического уровня. Отмечена необходимость применения к анализу интернет-коммуникации не только собственно лингвистических, но и лингвостатистических, квантитативных методов.
\end{abstract}

Ключевые слова: автороведческое исследование, биосоциальные признаки, интернет-дискурс.

\section{Theoretical framework of diagnostic techniques of legal authorship examination (on the material of written interpersonal electronic communication)}

\author{
E. A. Zhdanova \\ Kalashnikov Izhevsk State TechnicalUniversity \\ Studencheskaya St. 7, Izhevsk, 426069, Russian Federation.E-mail: zhdanovaea@gmail.com
}

\begin{abstract}
The article discusses the Internet discourse in the aspect of authorship problems. The article outlines the specific features of modern computer communication, the genre features of interpersonal correspondence that affects the language of electronic messages. It is argued that in the Internet discourse the speech skills of the authors are manifested specifically, which require s a different approach to the study of authorship in this sphere of communication. Some features to be noted by the expert when working with Internet communications are singled out. The article presents the results of the analysis of messages in social networks and messengers, the purpose of which was to identify speech features that indicate the specific biological and social characteristics of the authors. Messages in social networks and instant messengers are treated as phenomena of the same order, since they are close functionally, since they serve mainly for the informal exchange of information between recipients familiar with each other, and presuppose primarily written dialog. The case study analyses messages written by men and women aged 12 to 72 years old, with different education, employed in various spheres, both citizens of Russia and other countries. The analysis revealed lexical, phraseological, grammatical, stylistic, spelling, punctuation features of the authors' messages, depending on their age, place of birth, knowledge of the Russian language, level of education and general culture, job and occupation. The
\end{abstract}


characteristic features of the lexical level are recognized as the most illustrative. The article argues that not only linguistic methods proper but also statistical, quantitative methods should be applied the analysis of the Internet communication.

Key words: authorship research, biosocial features, the Internet discourse.

Использование сети Интернет в качестве канала коммуникации началось несколько десятилетий назад и неуклонно активизируется. Появляются новые формы и возможности общения, которые влекут за собой возникновение новых языковыхспособов выражения. В связи с этим в лингвистике появляется новый объект изучения, обозначаемый как электронное общение, интернеткоммуникация, компьютерный дискурс.

Целью данной работы является анализ особенностей коммуникации в социальных сетях и мессенджерах, которые могут быть использованы в качестве теоретической основы при проведении лингвистической автороведческой экспертизы текстов интернеткоммуникации.

Материалом для анализа послужили сообщения из личной переписки автора работы и членов его семьи в социальных сетях ВКонтакте, Одноклассники и в мессенджере Viber. На наш взгляд, такие формы общения, как переписка в соцсетях и мессенжерах, близки функционально, так как служат в основном для неформального обмена информацией между знакомыми друг с другом адресатами, предполагают диалогическое общение преимущественно в письменной форме. В сфере анализа оказались сообщения, написанные лицами мужского и женского пола в возрасте от 12 до 72 лет, имеющими различное образование, занятыми в разных сферах деятельности, являющимися гражданами России и некоторых других стран.

На современном этапе развития интернет-коммуникация становится все более разнообразной и разножанровой. В зависимости от условий и функций общения, взаимоотношений коммуникантов компьютерный дискурс приобретает разные формы, пользователи выбирают различные средства выражения. Например, если электронная почта имеет статус официального канала связи со свойственным ей этикетом и деловым стилем общения, то язык интернет-чатов остается неформальным, отражает специфические особенности разговорной речи.

Одним из важных факторов, влияющих на язык общения в интернете, является взаимодействие устной и письменной форм речи. В классическом понимании устная и письменная формы выполняют разные функции и, следовательно, имеют различные характеристики. Однако распространение современных коммуникационных технологий привело к тому, что функции, изначально присущие исключительно устной речи, стали характерными и для письменной. Чаты в социальных сетях и мессенджеры служат для непосредственного общения, быстрого обмена информацией, передачи эмоций коммуникантов, находящихся на расстоянии. Отсутствие тарификации и лимита на число знаков в отсылаемых сообщениях приводит к неограниченности объема и количества посланий, а также к тому, что у пользователя пропадает необходимость корректировать, сокращать сообщения ради экономии: если адресат не поймет послание, то может переспросить, уточнить.

Возможность непосредственного контакта и свобода формы выражения приводят к тому, что автор, создавая письменный текст, осмысляет его как аналог устного высказывания и строит его как устное сообщение: использует большое количество стилистически сниженной лексики, не заботится о четком грамматическом оформлении предложений, невнимательно относится к орфографической и пунктуационной подаче материала (по нашим наблюдениям, некоторые авторы используют только те знаки препинания, которые выполняют эмоциональную функцию). Эмоции, для выражения которых в устной речи служат интонация и невербальные сигналы (смех, стон и т.п.), в письменной заменяются смайликами и другими картинками, фигурами, составленными из пунктуационных знако в, междометиями и звукоподражаниями (Вау! Апхахахах! Хе-хе). В связи с этим некоторые ученые говорят о появлении благодаря интернету особой устно-письменной формы речи [Горошко 2012]. Некоторые исследователи относят подобные формы коммуникации к числужанров естественной письменной речи [Лебедева 2001].

В качестве подтверждения тезиса о том, что пользователи мессенджеров воспринимают переписку как устное общение, приведем пример из чата в Viber родителей и руководителя детского ансамбля:

[Юлия Николаевна (руководитель)]: Внимание, уважаемые родители! 3 и 4 марта у нас концерты! В Филармонии и у нас в школе. 3 марта встречаемся в 13.30 в ШКОЛЕ в костюмах, туфли, деньги или проездной на троллейбус! В 16.30 начало КОНЦЕРТА! Закончится концерт в 18.00!!! 4 марта в 17.00 распевка, в 18.00 - концерт! Концертный костюм. Прошу оздоровить детей и проследить, чтобы они выспались)))

[Андрей (один из родителей)]: Юлия Николаевна! Очень много информации. Хочется конкретики. Сегодня во сколько Ждану быть в филармонии в костюме?

Данный фрагмент показывает, что несмотря на сохранение в чате письменного сообщения руководителя, в котором информация представлена вполне четко и структурированно, и возможность его перечитать, адресат для уточнения использует такти ку переспросов, которая характерна для устного общения и вызвана такими свойствами устной речи, как необратимость и завершенность во времени.

Социальные сети и мессенджеры не являются официальным каналом передачи информации, это усиливает впечатление живого неформального диалога, поэтому даже переписка незнакомых друг с другом коммуникантов или людей, состоящих в деловых отношениях, в данных условиях воспринимается как неофициальная, что отражается на выборе лексического, грамматического, стилистического и графического оформления сообщений. Часто послания оказываются короткими, как реплики в устном диалоге, вербальный ответ может быть заменен смайликом или каким-либо изображением, что приводит к креолизации диалога.

Стоит отметить и широкую тематику неофициальной интернет-переписки: коммуниканты могут обсуждать как бытовые темы, что характерно для бесед в разговорном стиле, так и деловые, профессиональные вопросы или, например, прочитанные книги и просмотренные фильмы, что расширяет круг используемых лексических средств и стилистических ресурсов языка. Таким образом, языковые средства, задействованные в сообщениях соцсетей и мессенджеров, выходят за рамки обиходно-бытового общения.

Обратим внимание и на то, что в отличие от многих других форм интернет-коммуникации (сайтов, блогов, электронной почты $и$ др.) общение в соцсетях и мессенджерах, несмотря на опосредованность компьютером или другими устройствами, оснащенными доступом в интернет, в принципе не предполагает дистантности адресата и адресанта, особенно во временном плане: пишущий зачастую обращается к лицу, которое находится в сети (online), и рассчитывает на моментальный ответ. Этот фактор сближает письменную коммуникацию в соцсетяхи мессенджерах с видеозвонками, делает общение в данном формате непосредственным.

Указанные черты, обусловленные функциональными особенностями сообщений в соцсетях и мессенджерах, определяют их своеобразие и необходимость особого подхода к иханализу. 
Применительно к общению в соцсетях и мессенджерах встает вопрос о том, как соотнести данный дискурс с понятием текст Можно ли считать текстом каждое отдельное сообщение, опираясь на то, что единичная «реплика» не всегда приводит к развернутому диалогу или даже вызывает ответную реакцию? Или текстом будет являться весь диалог, объединенный тематикой (не всегда обсуждается одна тема), тональностью, коммуникативной ситуацией, связный, цельный, ограниченный временем? Такой интернетдиалог близок к понятию текста-разговора как одного из видов разговорных текстов в концепции О. Б. Сиротининой или может быть назван неканоническим текстом в терминологии Т. В. Матвеевой [Кожина 2012: 442-446]. Существенное отличие от канонического текста заключается в разносубъектности такого речевого образования, что осложняет применение к нему текстологических методов при проведении автороведческой экспертизы. Для описания характеристик одного из авторов такого текста необходимо извлечь его реплики и рассматривать их в совокупности, однако для анализа некоторых показателей придется учитывать их связь с репликами собеседника.

Разработка методов авторизации письменного текста на основе лингвистических признаков началась в СсСР во второй половине XX в. В 1976 г. Г. Л. Грановский отмечает, что письменная речь дает бо́льшие возможности по определению автора текста, нежели те, что предполагает почерковедческая экспертиза [Грановский 1976: 3], которая, в частности, не применима к печатным текстам. Однако несмотря на большое количество разносторонних исследований письменной речи, точного алгоритма действий для эксперта не существует.

В качестве основной методики анализа в данной работе применяется классификация языковых, дискурсивных и интеллектуальных навыков письменной речи, приведенная в пособии С. М. Вула «Судебно-автороведческая идентификационная экспертиза: методические основы» [Вул 2007]. Однако при анализе таких специфических текстов, как сообщения в соцсетях и мессенджерах, эксперт не может применить весь спектр оценочных средств и методов, разработанных для исследования письменной речи.

С другой стороны, фактор «разговорности», эмоциональности, «неотредактированности» интернет-сообщений дает эксперту новые возможности. При анализе такого материала можно обратить внимание на следующие признаки написания сообщений:

- количество опечаток и нелепых ошибок, которые нельзя объяснить орфографическими правилами,

- согласованность предложений (насколько автор вообще обращает внимание на языковое оформление текста);

- манера передавать мысль (описывать ситуацию) одним сообщением или разбивать ее на несколько «синтагм»;

- анализ графического оформления: использование «смайликов» и других картинок, предпочтение замены их знаками препинания, наличие пробелов между словами, использование букв ё и ъ, которых нет в раскладке некоторых гаджетов, наличие или отсутствие заглавных букв, использование текстового редактора, помогающего в правописании, но иногда заменяющего слова, и т. д.

Все эти признаки, отчасти сближающие анализ сообщений с почерковедческой экспертизой, могут дать представление о манере письма автора и помочь при идентификационной экспертизе, а также указать на некоторые психологические и социальные характеристики пишущего.

Также отметим, что к текстам интернет-коммуникации, существующим в электронном виде, удобно применять лингвостатистические методы, и при достаточной их проработанности и теоретической обоснованности тексты сообщений одного лица, представленные в совокупности, могли бы быть подвергнуты квантитативному анализу по ряду релевантных признаков, на основании которого можно было бы делать выводы о специфических речевых чертах данного автора и устанавливать авторство спорных (конфликтных) текстов сообщений. Применение лингвостатистических методов для определения некоторых биосоциальных признаков авторов текстов интернет-коммуникации является одним из развивающихся направлений современной прикладной лингвистики [см., например, Верхозин 2013; Горошко 2004; Красса 2013; Романов, Мещеряков 2011; Рыжкова 2015, Туманова 2011].

Но стоит подчеркнуть, что при анализе электронных сообщений, как при исследовании любого текстового материала, необходимо учитывать экстралингвистические показатели. Некоторые параметры сообщений: объем текста, выбор слов, ошибки и опечатки - могут зависеть от внеязыковых факторов, таких как желание / нежелание, возможность / невозможность общаться, близость в отношениях между коммуникантами, тема переписки.

В процессе анализа были выявлены речевые особенности авторов, указывающие на определенные биосоциальные признаки.

1. Речевые особенности сообщений информантов, для которых русский язык не является родным.

Большинство авторов проанализированных нами сообщений являются жителями города Ижевска и Удмуртской Республики. Это представители русской, удмуртской или татарской национальности, для которых русский является родным или одним из двух основ ных языков общения. Русско-удмуртский и русско-татарский билингвизм распространены в данном регионе, что в большинстве случаев не отражается на письменной речи в интернет-переписке, по крайней мере в нашем материале таких примеров не встретилось. Однако в круг анализируемых сообщений попали и тексты, написанные лицами, для которых русский язык не является родным: это обучающиеся в Ижевске студенты из Узбекистана и Дагестана. Даже при хорошем владении русским языком в письменной речи данные авторы делают ошибки (орфографические и пунктуационные, грамматические и лексические), которые сложно представ ить в тексте, написанном человеком, для которого русский язык является родным. Данные сообщения отличаются от всех остальных даже при небольшом объеме текста.

Приведем несколько примеров

Ж, 20 л. (русский язык знает с детства):

...можно завтра отпраситься, у меня высокая температура, заразилась грипом. Если температура снизится, я приду на пару не смотря на болячку, обещаю!

Ведемосте есть нона зачеткуне проставлена просто

M, 20 л.

Я Бунёдбек. Я сильно простудился сегодня, кажется грипп. Думаю завтра не могу пойти на уроки! скажите пожалуйста.

ж, 23 г.

По поводу девушки. Они точно переведут учёбу в узбекистан. Пожалуйста прстовче очень им по русскому языку. У них первый и второй семестр не посовлено. У Саидова Махфирата и Якубовой Айгула

Ж, 20 лет (пример речи лица, очень слабо владеющего русским языком):

Можно ли я сегодня оплачу 20 тисече потом 22 тис уменя сейчас только 20тисече есть за проезда тоже нет денег по этому не было на вашу паре

Особенно сложно носителям тюркских языков дается грамматическое оформление предложений, отсутствие знаний о русском правописании, которые дают в русских школах, отражается в орфографическом и пунктуационном оформлении сообщений. Рассматривая отличия речи людей, говорящих на других национальных языках, Грановский отмечает также возможность 
использования такими авторами слов родного языка в русском тексте [Грановский 1976], однако в нашем материале таких случаев не обнаружено. Зарубежные студенты четко воспринимают русский язык как иностранный, поэтому для их речевой практики не характерна интерференция языков, которая свойственна билингвам.

Отметим также, что лица, недолго проживающие в России, недостаточно владеют стилистическими и этикетными нормами, поэтому могут написать малознакомому старшему и более высокопоставленному человеку (преподавателю) «Привет!», «Как ваши дела?» и т. п. Считаем, что речь нерусскоязычных авторов практически невозможно перепутать с речью русскоговорящего человека и сложно подделать.

2. Речевые особенности информантов, определяющие их место жительства (происхождение).

Как известно, русский язык имеет не только социальную, но и территориальную дифференциацию. Диалектные особенности речи характерны прежде всего для жителей сельской местности, однако и жители городов употребляют в своей речи местные слова локализмы, - использование которых наблюдается в определенном регионе или населенном пункте и которые неизвестны за пределами данной местности. В городах такие элементы относятся к просторечию и характерны для разговорной речи. Просторечие традиционно складывается на базе диалектов, это и обеспечивает его местное своеобразие. Использование подобных локальных элементов в речи указывает на место жительства или происхождение говорящего.

В связи с неофициальностью и непосредственностью общения в соцсетях и мессенджерах в сообщениях коммуникантов, родившихся и живущих в Ижевске, иногда встречаются локализмы:

На дачу мы едем сегодня у мелкого др (М. 19 л.)

Мелкий - младший (о брате) [Прокуровская 1996: 90).

- Начем мне ехать?

- На ОДНЁРКЕ) (Ж.138 л.)

- Еду на ОДНЁРКЕ (Ж.238 л.)

Однёрка-маршрут троллейбуса, трамвая № 1 [Прокуровская 1996: 51].

В этом диалоге двух женщин, имеющих высшее филологическое образование, графическое выделение слова подчеркивает шутливый характер сообщений. Просторечная лексема употребляется с иронией, коммуниканты осознают функциональностилистическую маркированность данной номинации. В то же время сам факт знания и употребления в речи данного элемента свидетельствует о местном происхождении обеих собеседниц: каждая знает, что адресат поймет данное сообщение и воспримет юмористический посыл.

В сообщениях жителей Ижевска встречается характерное для местной устной речи употребление в начале предложения частицы так, которая в русских говорах Удмуртии, отличающихся сильной редукцией безударного гласного, и в аналогичном просторечном произношении г. Ижевска звучит как дык или дк:

Дык я об этом и говорю (Ж. 38 л.)

Дк правильно все так-то (М. 19 л.)

Показателем того, что автор текста проживает в определенном населенном пункте, является также использование им неофициальныхискаженных урбанонимов, известныхтолько местным жителям:

Только чтоо весь талик эвакуировали (М. 18 л.)

Талик - ТЦ «Талисман» в г. Ижевске.

Сережа с детьми на молодежку едет... (Ж. 37 л.)

Молодёжка -улица Молодёжная в г. Ижевске.

А так в металлурге на пляжу (М. ок.30 л.)

Металлург - городок металлургов, неофициальное название одной из частей г. Ижевска.

В учебном пособии «Русская диалектология» А.Д. Черенкова обращает внимание читателей-студентов, будущих педагогов, на то, что диалектные черты произношения, в частности безударного вокализма, могут повлиять на особенности правописания учащихся [Черенкова 2014]. Основная масса русских говоров Удмуртии - окающие, что также может оказать влияние на написание слов с непроверяемой безударной гласной. В качестве подтверждения этой мысли, правда, с определенной долей условности, можно привести такой пример из сообщения молодого человека 18 лет, имеющего неоконченное среднее специальное образование, некоторое время проживавшего в сельской местности в Удмуртии:

...таких болбесов нет.

Отметим, что отсутствие диалектных черт и локализмов в речи, конечно, не может напрямую указывать на то, что пишущий является приезжим или родился и проживает в ином регионе: многие информанты избегают просторечных единиц как «непрестижных», «некультурных», старомодных. Но использование элементов, не характерных для языка данного региона, которым в местной речи соответствует иное обозначение, можно считать показателем того, что автор является приезжим или проживает в иной местности. Пример анализа такого случая (связанного с употреблением в разных регионах вариантов шаурма и шаверма) в тексте, представленном для лингвистической экспертизы, приведен в работе К.И. Бринева [Бринев 2005].

3. Речевые особенности информантов, демонстрирующие уровень образования и общей культуры.

В отношении текстов переписки в соцсетях и мессенджерах уровень реального владения автором письменной речью определить сложнее, поскольку, как уже отмечалось, данный вид коммуникации предполагает неформальное общение, в котором письмо сближается с устной речью.

Однако можно выделить некоторые речевые особенности, которые с большой вероятностью могут свидетельствовать об определенном уровне культуры автора.

Для авторов интернет-сообщений с низким уровнем культуры характерны:

- употребление без юмористической или эмоциональной интенции просторечных слов и выражений, которые люди с высоким культурным уровнем воспринимают как вульгарные:

Нам всем надо баблище;

- деминутивы, характерные для просторечия:

Свас денежки!

Мне пишет человечек Григорий;

- просторечные формы слов, которые являются ненормативными для русского языка:

А так в металлурге на пляжу;

В понедельник все скажу и по материалу и по денежке; 
- ошибки в сочетании главного слова с зависимым, в частности, неуместное употребление предлога по:

Как делишки по бабкам?

Что-тослышно по недтянникам?

- склонность к использованию речевых штампов, в том числе модных в интернет-среде общения (всё норм, сорян, ржу не могу). Такие выражения характерны для школьников и студентов, имеющих недостаточный уровень образования и речевой культуры.

В сообщениях людей с высоким уровнем культуры можно отметить такие лексико-фразеологические явления, как тропы, архаизмы, употребляемые для создания комического эффекта, фразеологические обороты, цитаты:

Подобных рецептов в сетилегион, там вообще вакханалия;

Как ваше здоровье, сударь?

Наверно, мне не комильфо на своей странице эту ссылку размещать.

Куда катится мир...

Выезжать можно до поры до времени, но ск верёвочке не виться...

Что касается грамматики, то в интернет-сообщениях образованных авторов с высокой речевой культурой можно отметить сложные предложения с разнообразной пунктуацией (в частности, с уместным использованием знаков «-» и «:»), деепричастные обороты, характерные для книжной речи:

Чтохарактерно: такие посты обычно в виде необ'ятных простынь выкладывают. Балакина тоже от помета удержат ься не может - растекается мыслию по древу

Отчаявшись, люди верят всему.

4. Речевые особенности информантов, обусловленные ихпрофессией или родом занятий.

Как показал анализ текстов сообщений в соцсетях и мессенджерах, в этом жанре основным, наиболее явным показателем профессии также является использование профессиональной или профессионально-жаргонной лексики. Приведем несколько примеров:

Термоголовки или просто отсекайки (строитель);

...Помочь переврезать Пушкинскую (сантехник);

Такая глупая ситуация... из за которой я лишился увала (военнослужащий);

Из-за того что был кривой переходник был не чистый звук а ультра дисторшен (музыкант).

Также в интернет-переписке могут использоваться сокращения, которые употребляются в определенной профессиональной среде:

Гвлв лист везти после бетона. (строитель)

Гвлв - гипсоволокнистый лист влагостойкий.

...начисляем зп, налоги 15 платить будем? (бухгалтер)

3п-заработная плата.

Стоит обратить внимание также на следующий факт: в подавляющем большинстве случаев даже те авторы сообщений, которые не имеют высокого уровня образования и обладают низким уровнем культуры речи, абсолютно грамотно пишут сложные специальные термины. Приведем в качестве примера типичное сообщение сантехника:

Компрессором да воздохом её так хоть сливать нече не надо

Некоторые сферы деятельности оказывают влияние не только на лексико-фразеологические и орфографические, но и на грамматические навыки людей, имеющих к ним отношение. Например, в нашем распоряжении оказались сообщения в социальных сетях, авторами которых являются отставной военный и солдат, проходящий срочную службу в армии. Помимо соответствующей лексики и фразеологии (прапор, на гражданке, здравия желаю!), только в речи этих людей в качестве ответов на просьбы и достаточно развернутые сообщения близких людей (родственников и бывших одноклассников) были отмечены краткие стандартные ответы «по уставу»: Так точно, Принято, Понял ит. п.

Заметим, что речь филологов, помимо содержания специфических лексических элементов, обычно отличается всесторонней грамотностью, то есть высоким уровнем развития всехязыковых навыков, что тоже можно считать отпечатком профессии. Хотя и в речи данной категории лиц встречаются ставшие уже традиционными «разговорные» сокращения - упрощенные написания слов, передающие их звучание при «неполном» произношении, характерном для устной разговорной речи: щас, седня, че и т. д.

5. Речевые особенности информантов, обусловленные возрастом.

Возрастная дифференциация языкаявляется известным и достаточно хорошо изученным явлением.

На лексико-фразеологическом уровне возраст автора старшего поколения могут выдавать историзмы и архаизы, использование прецедентных текстов, актуальных в прошлом, и т. д. (в нашем материале встретилось обозначение Главснаб в речи женщины 72 лет).

В сообщениях молодых людей используются слова, относящиеся к молодежному жаргону:

У меня на два дня чилл домашний (Ж., ок.20 л.);

Щас заряжу телефон прочекаю где ты (М., 15 л.).

Школьники употребляют школьный сленг:

Просто я неделю тройбаны таскал (М. 14 л.);

У тебя родаки надеюсь не присутствуют? (М. 15 л.)

Молодые люди чаще используют слова и выражения из особого «сетевого» сленга: Ору! Ржунимагу! Фигасе! (М., 20 л.).

Что касается грамматических, орфографических и пунктуационных навыков, то по отношению к ним можно выделить общую тенденцию: старшее поколение, чьи языковые навыки формировались на примерах письменных текстов из художественной литературы, научной, деловой и отредактированной публицистической речи, по привычке стремится оформлять свою письменную речь грамотно как в плане правописания, так и в аспекте построения предложений. Молодое поколение, с детских лет общающееся в социальных сетях на том «устно-письменном языке», который формируется в этой сфере достаточно давно, относится к оформлению письменного электронного текста с большим пренебрежением.

В речи учеников средней школы к речевым недочетам, обусловленным невниманием, равнодушием к оформлению текста сообщения, добавляются ошибки, связанные с незнанием некоторых правил орфографии и пунктуации. Как показали наблюдения, сообщения людей разного возраста могут значительно различаться в стилистическом плане. Например, молодые люди наиболее активно употребляют в электронных сообщениях нецензурные слова, причем зачастую пишут их полностью. Люди более старшего возраста используют матерные слова реже, обычно сокращают и видоизменяют их: хз, блеать, зае...л, збс и т. п. Аналогичное 
использование нецензурных выражений отмечено и в сообщениях детей среднего школьного возраста: по-видимому, они еще стесняются писать такие слова или боятся, что родители зайдут на их страницув социальной сети и увидят эти тексты.

Для сообщений представителей старшего поколения в социальной сети «Одноклассники» характерно сохранение стилистики дружеских посланий: во многих случаях это развернутые тексты, начинающиеся с приветствия и обращения (Здравствуй, дорогая Аллочка!), далее может следовать информация о состоянии здоровья, о последних событиях в жизни автора, об общих знакомых и т.д., в завершении может использоваться концовка типа Целую!. Такие тексты, как правило, оформлены с максимальным соблюдением норм русского языка (в зависимости от коммуникативных компетенций каждого конкретного автора). Часто в связи с праздником люд и старшего возраста отправляют друзьям стикеры с поздравлениями и пожеланиями. То есть такие авторы переносят на электронную переписку черты, характерные для бумажных писем, которыми они обменивались с друзьями до появления интернет-коммуникации. Такие тексты заметно контрастируют с обрывочными сообщениями, которыми «перебрасывается» в соцсетяхмолодежь.

\section{Выводы}

В результате проведенного анализа было выявлено, что наиболее показательными в электронной межличностной переписке являются признаки лексико-фразеологических навыков автора. Различные частные признаки, касающиеся употребления того или иного разряда слов, широты словарного запаса, могут помочь определить место жительства, уровень образования, профессию, возраст и пол пишущего. Несколько иной в применении к текстам интернет-коммуникации представляется роль грамматических, орфографических и пунктуационных навыков: неформальный характер общения коммуникантов, диалогичность, общая сниженность стилистики общения часто ведут к ослаблению рефлексии автора в отношении к построению и оформлению текста, поэтому речевые нарушения не всегда являются показателем низкой речевой культуры пишущего. Кроме того, дробность текста, обусловленная его диалогичностью, эмоциональностью, стремлением ускорить передачу информации, затрудняет подсчет ошибок, учитывающий объем текста.

Стоит отметить, что различные характеристики автора, такие как возраст, уровень образования, профессия, пол необходимо изучать в совокупности, учитывая другие факторы, такие как жанр общения, тематика дискурса, адресат и т. п. Современная электронная коммуникация формирует новые способы и средства выражения и требует применения к ним несколько измененных лингвистических параметров, разработки новых методов исследования на стыке лингвистических и современных квантитативных методов, которые могут обеспечить компьютерные технологии.

\section{Литература}

1. Бринев К. И. «Русский, решай...». Юрислингвистика-6: Инвективное и манипулятивное функционирование языка. Барнаул, 2005. - C. 290-303.

2. Верхозин С. С. К вопросу о лингвотеоретических основах методик авторизации текста. Ученые записки Забайкальского государственного университета. Серия: Филология, история, востоковедение. Чита, $2013 . \quad$ Bып. 2 (49). URL: http://cyberleninka.ru/article/n/k-voprosu-o-lingvoteoreticheskih-osnovah-metodik-avtorizatsii-teksta

3. Вул С. М. Судебно-автороведческая идентификационная экспертиза: методические основы. Харьков, 2007.

4. Горошко Е. И. Изучение электронного дискурса в судебном речеведении. 2004. URL: http://www.textology.ru/article.aspx?ald=44

5. Горошко Е.И. Современные интернет-коммуникации: структура и основные характеристики. M.., $2012 . \quad$ URL: http://www.textology.ru/article.aspx?ald=232

6. Грановский Г. Л. Использование признаков письменной речи в криминалистической экспертизе. М., 1976.

7. Кожина М. Н., Дускаева Л. Р., Салимовский В. Я. Стилистика русского языка. М., 2012.

8. Красса С.И. Методика и инструментарий атрибуции текста в автороведческой экспертизе. Тамбов 2013. http://www.gramota.net/materials/1/2013/10/30.html

9. ЛебедеваН.Б. Естественная письменная русская речь как объект лингвистического исследования. Барнаул, 2001. URL: http://www.uni-altai.ru/Journal/vestbspu/2001/gumanit/PDF/lebedeva.pdf

10. Прокуровская Н. А. Город в зеркале своего языка: На языковом материале г. Ижевска. Ижевск, 1996.

11. Романов А. С., Мещеряков Р. В. Определение пола автора короткого электронного сообщения. Компьютерная лингвистика и интеллектуальные технологии: сб. Междунар. конф. по компьютерной лингвистике "Диалог". 2011. URL: http://www.dialog21.ru/digests/dialog2011/materials/ru/pdf/55.pdf

12. Рыжкова Е. С. Проблемы автороведческой классификационной экспертизы текстов интернет-коммуникации. Филологические науки. Вопросы теории и практики. Тамбов, 2015. № 6 (48): в 2-хч. Ч. І. - С. 130-133.

13. Туманова K. С. Алгоритм классификации текстов на русском языке по возрасту и гендерному признаку автора. CПб., 2011. URL: http://se.math.spbu.ru/SE/diploma/2011/Tumanova\%20Kristina\%20-\%20slides.pdf

14. Черенкова А. Д. Русская диалектология. Воронеж, 2014.

\section{References}

1. Brinev, K. I. (2005). Russian, decide... [Russkij, reshaj...]. Invektivnoe i manipulyativnoe funkcionirovanie yazyka. Invective and manipulative functioning of a language. Legal Linguistics, 6, 290-303 (n Russian).

2. Verhozin, S. S. (2013). To the question of linguistic-theoretical foundations of text authorization techniques [K voprosu o lingvoteoreticheskih osnovah metodik avtorizacii teksta]. Uchenye zapiski Zabajkal'skogo gosudarstvennogo universiteta. Seriya: Filologiya, istoriya, vostokovedenie. - Scientific notes of the Transbaikal State University. Series: Philology, History, Oriental Studies. Chita, 2(49). Available from: http://cyberleninka.ru/article/n/k-voprosu-o-lingvoteoreticheskih-osnovah-metodik-avtorizatsii-teksta (in Russian).

3. Vul, S. M. (2007). Forensic identification of experts: methodological foundations [Sudebno-avtorovedcheskaya identifikacionnaya ekspertiza: metodicheskie osnovy]. Xar'kov (in Russian).

4. Goroshko, E. I. (2004). The study of electronic discourse in forensic science [Izuchenie elektronnogo diskursa v sudebnom rechevedenii]. Available from: http://www.textology.ru/article.aspx?ald=44 (in Russian). 
5. Goroshko, E. I. (2012). Modern Internet communications: structure and basic characteristics [Sovremennye internet-kommunikacii: struktura i osnovnye harakteristiki]. Moscow. Available from: http://www.textology.ru/article.aspx?ald=232 (in Russian).

6. Granovskij, G. L. (1976), Use of signs of written speech in forensic examination [Ispol'zovanie priznakov pis'mennoj rechi v kriminalisticheskoj ekspertize]. Moscow (in Russian).

7. Kozhina, M. N., Duskaeva, L. R., Salimovskij, V. Ya. (2012). Stylistics of the Russian language [Stilistika russkogo yazyka]. Moscow (in Russian).

8. Krassa, S. I. (2013). Methodology and toolkit for text attribution in expert analysis [Metodika i instrumentarij atribucii teksta $v$ avtorovedcheskoj ekspertize]. Tambov. Available from: http://www.gramota.net/materials/1/2013/10/30.html (in Russian).

9. Lebedeva, N. B. (2001). Natural written Russian speech as an object of linguistic research [Yestestvennaya pis'mennaya russkaya rech' kak ob"yekt lingvisticheskogo issledovaniya]. Barnaul. Available from: http://www.uni-altai.ru/Journal/vestbspu/2001/gumanit/PDF/lebedeva.pdf (in Russian).

10. Prokurovskaya, N. A. (1996). The city in the mirror of its own language: On the language material of Izhevsk [Gorod v zerkale svoyego yazyka: Na yazykovom materiale goroda Izhevska. Izhevsk (in Russian).

11. Romanov, A. S. (2011). Meshcheryakov R. V. Sex determination of the author of a short electronic message [Opredeleniye pola avtora korotkogo elektronnogo soobshcheniya]. Komp'yuternaya lingvistika i intellektual'nyye tekhnologii: sb. Mezhdunar. konf. po komp'yuternoy lingvistike "Dialog" - Computational linguistics and intellectual technologies. Proceed. Int. Sc. Conf. on Computer Linguistics "Dialogue". Available from: http://www.dialog-21.ru/digests/dialog2011/materials/ru/pdf/55.pdf (in Russian).

12. Ryzhkova, Ye.S. (2015). Problems of the authoring classification examination of texts of Internet communication [Problemy avtorovedcheskoy klassifikatsionnoy ekspertizy tekstov internet-kommunikatsii]. Filologicheskiye nauki. Voprosy teorii i praktiki - Philological sciences. Questions of theory and practice , 6(48), I, 130-133 (in Russian).

13. Tumanova, K. S. (2011). Algorithm for the classification of texts in Russian by age and gender of the author [Algoritm klassifikatsii tekstov na russkom yazyke po vozrastu i gendernomu priznaku avtora]. St. Petersburg. Available from: http://se.math.spbu.ru/SE/diploma/2011/Tumanova\%20Kristina\%20-\%20slides.pdf (in Russian).

14. Cherenkova, A. D. (2014). Russian dialectology [Russkaya dialektologiya]. Voronezh (in Russian).

\section{Citation:}

Жданова Е.А. Теоретические основы диагностических методик сүдебного автороведения (на материале письменной ме жличн остн ой эл ектр онн ой коммуникации). // Юрислингвистика. -2019. - 13. -С. $18-24$.

Zhdanova, E.A. (2019). Theoretical framework of diagnostic techniques of legal authorship examination (on the material of writ ten int erpersonal el ec tro nic communication). Legal Linguistics, 13, 18-24.

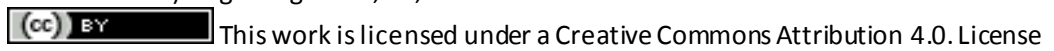

